\title{
Starch granules as Pickering emulsifiers: role of octenylsuccinylation and particle size
}

\begin{abstract}
The present study aimed at investigating the effects of octenylsuccinylation and particle size on the emulsifying properties of starch granules as Pickering emulsifiers. Starch spherulites $(1-5 \mu \mathrm{m})$, native rice starch $(5-10 \mu \mathrm{m})$, waxy maize starch $(10-20 \mu \mathrm{m})$ and waxy potato starch (20-30 $\mu \mathrm{m})$ were modified with octenylsuccinic anhydride. Results showed that octenylsuccinylation caused a significant increase in the contact angle, and there was a weak positive linear correlation with the emulsifying capacity of the starch granules. After octenylsuccinylation, smaller particles of octenylsuccinate-starch granules exhibited better emulsifying properties with smaller droplet size and lower creaming index. Overall, both octenylsuccinylation and particle size have important effects on the emulsifying properties of starch granules as Pickering stabilizers. This study could be useful in the design and development of starch-based Pickering emulsifiers, and provide potential applications in the food and pharmaceutical industries.
\end{abstract}

Keyword : Emulsifying properties; Octenylsuccinylation; Particle size; Pickering emulsions; Starch granule. 